\title{
Widespread late Mesozoic to Recent remagnetization of Paleozoic and lower Triassic sedimentary rocks from South China
}

\author{
DENNIS V. KENT ${ }^{1}$, ZENG XIANGSHAN $^{2}$, ZHANG WEN YOU $^{\dagger}{ }^{2}$ and NEIL D. \\ OPDYKE $^{3}$

\footnotetext{
${ }^{1}$ Lamont-Doherty Geological Observatory and Department of Geolugical Sciences of Columbia University, Palisades, NY IO964 (U.S.A.)

${ }^{2}$ Department of Geology, Academia Sinica, Beijing (P.R. of China)

${ }^{3}$ Department of Geology, University of Florida, Gainesville, FL 3261I (U.S.A.)
}

(Received February 19, 1986; revised version accepted July 28, 1986)

\begin{abstract}
Kent, D.V., Zeng, X., Zhang, W.Y. and Opdyke, N.D., 1987. Widespread late Mesozoic to Recent remagnetization of Paleozoic and lower Triassic sedimentary rocks from South China. In: D.V. Kent and M. Krs (Editors), Laurasian Paleomagnetism and Tectonics. Tectonophysics, 139: 133-143

Paleomagnetic results are described from eighteen formations sampled in the Nanjing (Jiangsu Province) and Yichang (Hubei Province) areas of South China. The marine platform carbonates and clastics range in age from early Cambrian to early Triassic. Progressive alternating field and/or thermal demagnetization analyses reveal predominantly single component magnetizations, sometimes of both normal and reverse polarity. These magnetizations, isolated in 457 of the 549 samples studied, typically have directions in geographic coordinates coincident with late Mesozoic to Recent fields. A secondary origin for the magnetizations is supported by negative fold tests in several units. A lower Carboniferous, and possibly a lower Triassic limestone may have escaped the pervasive remagnetization; if the remanences isolated are indeed prefolding, a large counterclockwise tectonic rotation of the Nanjing area is implied by comparison with available Carboniferous and Triassic paleopoles reported from elsewhere in South China. This rotation may have been associated with Mesozoic left-lateral motion on the Tancheng-Lujiang fault zone.
\end{abstract}

\section{Introduction}

The paleocontinental positions of tectonic elements constituting eastern Asia for the Paleozoic are poorly known, especially by comparison with the Atlantic-bordering continents. Few paleomagnetic data obtained by modern techniques are available (e.g., McElhinny et al., 1981) although additional information is being developed (Lin et al., 1985). The plate tectonic evolution of eastern Asia, especially in the pre-Tertiary, is consequently not well documented.

In an effort to augment the sparse paleomagnetic data base for one of the major tectonic elements, the South China block or Yangtze craton, we collected oriented samples for paleomagnetic study from eighteen predominantly Paleozoic sedimentary formations exposed in two areas, in the vicinities of Yichang (Hubei province) and Nanjing (Jiangsu province) (Fig. 1). It would be pleasant to report that original magnetizations have been recovered from many of these rock units. Instead, we find evidence of pervasive remagnetization that apparently occurred in the late Mesozoic, reminiscent of the well-known problem of remagnetizations associated with culmination of orogeny documented in various other parts of the world. 


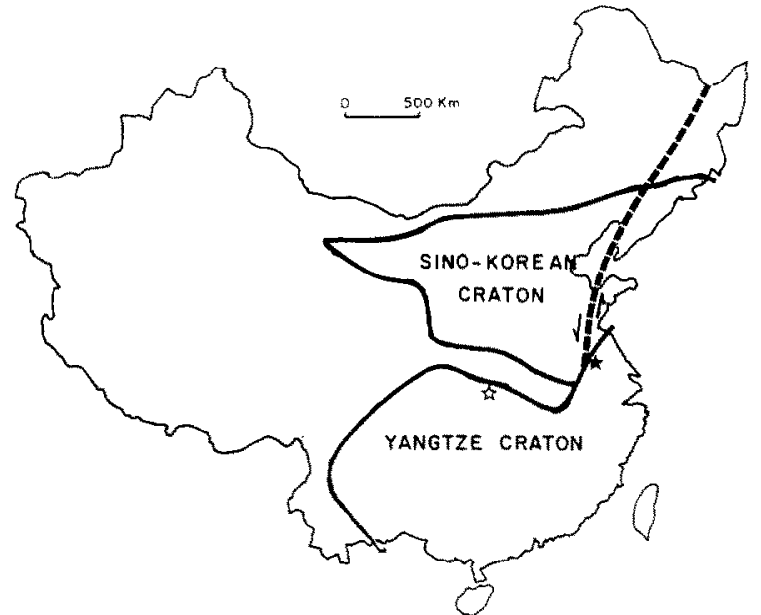

Fig. 1. Tectonic sketch map of China after Zhang et al. (1984). Heavy dashed line is Tancheng-Lujiang fault zone. Formations N1-N8 from Nanjing area (filled star) and Y1-Y10 from Yichang area (open star). See Table 1 for key to formation names and ages.

\section{Geologic setting and sampling}

An outline of the geological development of China in terms of plate tectonics was recently given by Zhang et al. (1984). The Yangtze craton was fundamentally consolidated after the Yangtze orogeny (ca. $850 \mathrm{Ma}$ ), much later than the stabilization (ca. $1750 \mathrm{Ma}$ ) of the Sino-Korean craton (North China block) with which it is sutured on the north, across the Qinling foldbelt. The basement of the Yangtze craton is overlain by a sedimentary cover, starting with continental molassetype redbeds and glacial deposits of the late Precambrian Sinian System and a conformable platform sequence of Cambrian to Silurian marine carbonate and argillaceous rocks.

In the Yichang area, middle Silurian strata are disconformably overlain by middle and upper Devonian marine clastic deposits which in turn are overlain by lower Permian limestones with slight angular discordance. Cretaceous continental redbeds unconformably overlie the Paleozoic and lower to middle Triassic marine strata. The gentle folding evidently took place sometime in the interval from late Triassic to late Jurassic in this area.

In the Nanjing area, a similar stratigraphic sequence as in the Yichang area is observed, except that lower Carboniferous quartz sandstones and limestones and upper Carboniferous limes- tones are also present. In contrast to the Yichang area, however, folding consists of tight upright to overturned anticlines and more open synclines which include Triassic and lower to middle Jurassic in their cores. A stage of folding therefore occurred in late Jurassic or younger time.

A total of 549 oriented drill-core samples were analyzed in this study, distributed over 101 sites in the 18 formations. Sites are groupings of three or more independently oriented samples taken over several meters stratigraphically.

In the Yichang area, 309 samples come from 54 sites in ten formations that range in age from early Cambrian to early Permian, with only the Carboniferous System not represented. Bedding dips of the Yichang sampling localities range to only $24^{\circ}$ and are mostly less than $15^{\circ}$ so that there is little opportunity for fold tests.

In the Nanjing area, 240 samples come from 47 sites in eight upper Cambrian to lower Triassic rock units. Bedding dips at the Nanjing sampling localities range from about $45^{\circ}$ to near vertical and overturned. Unfortunately it was not possible on this field trip to sample any of the formations on different limbs of folds. There was, however, sometimes sufficient variation in bedding dips, usually about $15^{\circ}$ but in one case nearly $60^{\circ}$, at the available sampling localities to allow a tilt test on the magnetizations.

For convenience of discussion, the sampled formations will be referred to numerically, prefixed by $\mathrm{Y}$ for the Yichang localities and by $\mathrm{N}$ for Nanjing localities, keyed in Table 1 along with dominant lithologies, ages and the number of sites/samples collected from each.

\section{Paleomagnetic measurements}

Specimens $2.2 \mathrm{~cm}$ long were cut from the 2.5 $\mathrm{cm}$ diameter cores for measurement of the natural remanent magnetization (NRM) on either a twoaxis cryogenic or a computerized flux-gate magnetometer. At least one pilot sample per site was subjected to a detailed program of progressive demagnetization treatments using alternating field (AF) or thermal techniques to determine the most efficient method of resolving components of magnetization in the remaining samples. Components 
TABLE 1

Paleomagnetic results from Paleozoic and lower Triassic sedimentary formations of South China*

\begin{tabular}{|c|c|c|c|c|c|c|c|c|c|c|c|c|}
\hline \multirow{3}{*}{\multicolumn{2}{|c|}{ Rock unit (litho) }} & \multirow[t]{3}{*}{ Age } & \multirow[t]{3}{*}{$N$} & \multirow[t]{3}{*}{$n_{1} / n_{2}$} & \multicolumn{6}{|c|}{ Paleopole } & \multirow[t]{3}{*}{ Po } & \multirow[t]{3}{*}{$\mathrm{Ft}$} \\
\hline & & & & & \multicolumn{3}{|c|}{ geographic } & \multicolumn{3}{|c|}{ bedding } & & \\
\hline & & & & & ${ }^{\circ} \mathrm{N}$ & ${ }^{\circ} \mathrm{E}$ & $A_{95^{\circ}}$ & ${ }^{\circ} \mathrm{N}$ & ${ }^{\circ} \mathrm{E}$ & $A_{95}^{\circ}$ & & \\
\hline \multicolumn{13}{|c|}{ Yichang area, Hubei Province $\left(30^{\circ}-31^{\circ} \mathrm{N}, 111^{\circ}-112^{\circ} \mathrm{E}\right)$} \\
\hline Y1 & Shilongdong (ls) & $\mathrm{C}_{1}$ & 7 & $32 / 37$ & 63 & 181 & 12 & 51 & 173 & 12 & $\mathbf{N}$ & \\
\hline $\mathrm{Y} 2$ & Tanjiamiao (ls) & $\mathrm{C}_{2}$ & 4 & $18 / 19$ & 75 & 185 & 7 & 59 & 174 & 4 & $\mathrm{~N}$ & \\
\hline Y3 & Sanyoudong (dolo) & $\mathrm{C}_{3}$ & 3 & $13 / 15$ & 77 & 218 & 24 & 67 & 223 & 28 & $\mathbf{N}$ & \\
\hline Y4 & Nanjinguan (ls) & $\mathrm{O}_{1}$ & 8 & $37 / 40$ & 83 & 169 & 5 & 72 & 157 & 10 & $\mathrm{~N}$ & $-f$ \\
\hline Y5 & Guniutan (red. ls) & $\mathrm{O}_{2}$ & 1 & $10 / 12$ & 75 & 031 & 5 & 76 & 116 & 5 & $\mathrm{~N}$ & \\
\hline Y6 & Baota (red. ls) & $\mathrm{O}_{2}$ & 9 & $40 / 43$ & 74 & 050 & 9 & 76 & 094 & 10 & $\mathbf{N}$ & \\
\hline Y7 & Loureping (Is) & $S_{1}$ & 6 & $26 / 35$ & 65 & 187 & 13 & 53 & 189 & 13 & $\mathbf{N}$ & \\
\hline Y8 & Shamao (ss) & $S_{2}$ & 1 & $10 / 11$ & 67 & 238 & 8 & 63 & 224 & 8 & $\mathbf{N}$ & \\
\hline Y9 & Huang Jiateng (ss) & $\mathrm{D}_{3}$ & 9 & $33 / 46$ & 69 & 184 & 9 & 52 & 185 & 9 & $\mathbf{N}$ & \\
\hline Y10 & Qi Xia (ls) & $\mathbf{P}_{1}$ & 7 & $25 / 51$ & 63 & 189 & 5 & 50 & 190 & 5 & $N$ & \\
\hline \multicolumn{13}{|c|}{ Nanjing area, Jiangsu Province $\left(32^{\circ} \mathrm{N}, 118^{\circ} \mathrm{E}\right)$} \\
\hline N1 & Guanyitai (dolo) & $\mathrm{C}_{3}$ & 4 & $18 / 20$ & 79 & 094 & 11 & 22 & 115 & 28 & $\mathrm{~N}$ & $-f$ \\
\hline N2 & Lunshan (ls) & $\mathrm{O}_{1}$ & 13 & $62 / 65$ & 63 & 109 & 7 & -18 & 102 & 9 & $\mathrm{~N}$ & $-\mathbf{f}$ \\
\hline N3 & Koachipian (ss) & $\mathbf{S}_{1}$ & 5 & $16 / 29$ & 72 & 203 & 8 & 19 & 277 & 12 & $N / R$ & \\
\hline N4 & Wutung (ss) & $\mathrm{D}_{3}$ & 8 & $33 / 39$ & 71 & 193 & 11 & 18 & 279 & 10 & $N / R$ & \\
\hline N5 & Jinling (ls) & $\mathrm{Cl}$ & 5 & $27 / 27$ & 20 & 153 & 21 & 61 & 342 & 10 & $\mathrm{~N}$ & $+f ?$ \\
\hline N6 & Chuanshan (ls) & $\mathrm{Cu}$ & 1 & $5 / 5$ & 69 & 166 & 6 & 51 & 308 & 6 & $\mathbf{N}$ & \\
\hline N7 & Qi Xia (ls) & $P_{1}$ & 6 & $29 / 30$ & 62 & 166 & 8 & 52 & 298 & 10 & $N / R$ & $-f$ \\
\hline N8 & Chinglung (ls) & $\mathrm{Tr}_{1}$ & 5 & $23 / 25$ & 71 & 112 & 13 & 56 & 320 & 7 & $\mathrm{~N}$ & $+f ?$ \\
\hline
\end{tabular}

\footnotetext{
* Age of rock unit is indicated by $\mathrm{C}$ for Cambrian, $\mathrm{O}$ for Ordovician, $\mathrm{S}$ for Silurian, $\mathrm{D}$ for Devonian, $\mathrm{Cl}$ for lower and $\mathrm{Cu}$ for upper Carboniferous, $\mathrm{P}$ for Permian, and Tr for Triassic; subscripts 1, 2, and 3 refer to lower, middle and upper subdivisions. $N$ is the number of sites, $n_{1}$ is the number of samples with acceptable data to $n_{2}$ the number of samples measured. Palcopole positions and associated circles of confidence $A_{95}$ are calculated from magnetically and/or thermally cleaned site-mean VGPs (except Y5, Y8 and N6 which are calculated by sample VGPs), before (geographic) and after (bedding) tilt corrections. Po indicates polarity (N for normal, $N / R$ for normal and reverse polarity) and $F t$ is fold test, $-f$ for statistically-significant negative, $+f$ for positive, otherwise indeterminate.
}

of magnetization were recognized as linear progressions of demagnetization vector end-points on orthogonal plots (Zijderveld, 1967). Principal component analysis (Kirschvink, 1980) was used to estimate the direction represented by the colinear array of three or more data points defining the component of magnetization. In most samples the magnetizations were essentially univectorial and in these cases the origin was included in the analysis.

The rather straightforward demagnetization behavior found in these samples allows us to describe the results from the 18 formations in a concise way.

\section{Yichang}

After removal of spurious magnetizations in initial stages of demagnetization, the dominant component of NRM in the Cambrian to Permian rocks from Yichang is revealed as northerly with moderate downward inclination (Fig. 2). In the Cambrian carbonate formations Y1, Y2, Y3 (Fig. $2 \mathrm{a}, \mathrm{b}, \mathrm{c}$ ), the Silurian limestones, $\mathrm{Y} 7$ and $Y 8$ (Fig. $2 \mathrm{~g}, \mathrm{~h}$ ) and the Permian limestone Y10 (Fig. 2j), the NRMs have moderate coercivities and can be fully demagnetized by AF treatments of $60-80 \mathrm{mT}$. The NRMs of the Ordovician limestones (Y4, Y5 and Y6) typically have much higher coercivities, greater than $80 \mathrm{mT}$, and require thermal treatment to fully decompose the magnetizations. For Y4, 
thermal demagnetization at only $200^{\circ} \mathrm{C}$ is sufficient to effectively remove the high coercivity fraction of the NRM (Fig. 2d), and we surmise that high coercivity, low Curie point geothite is an important carrier of magnetization. In the rcddish-colored limestones $\mathrm{Y} 5$ and $\mathrm{Y} 6$, the same magnetization directions persist to above $575^{\circ} \mathrm{C}$ (Fig. 2e, f), consistent with some contribution from hematite. High demagnetization temperatures characterize especially the NRM of the Devonian hematitic sandstone $\mathrm{Y} 9$ (Fig. 2i); the erratic directions often seen above $625^{\circ} \mathrm{C}$ are attri- buted to viscous behavior related to magnetochemical alterations as inferred from greatly increased susceptibilities after heating to high temperatures.

\section{Nanjing}

There is more variability in the magnctizations of the eight formations studied in the Nanjing area (Fig. 3). Four units (N1, N2, N6, N8) again have essentially univectorial NRM with consistently northerly and downward directions (Figs.
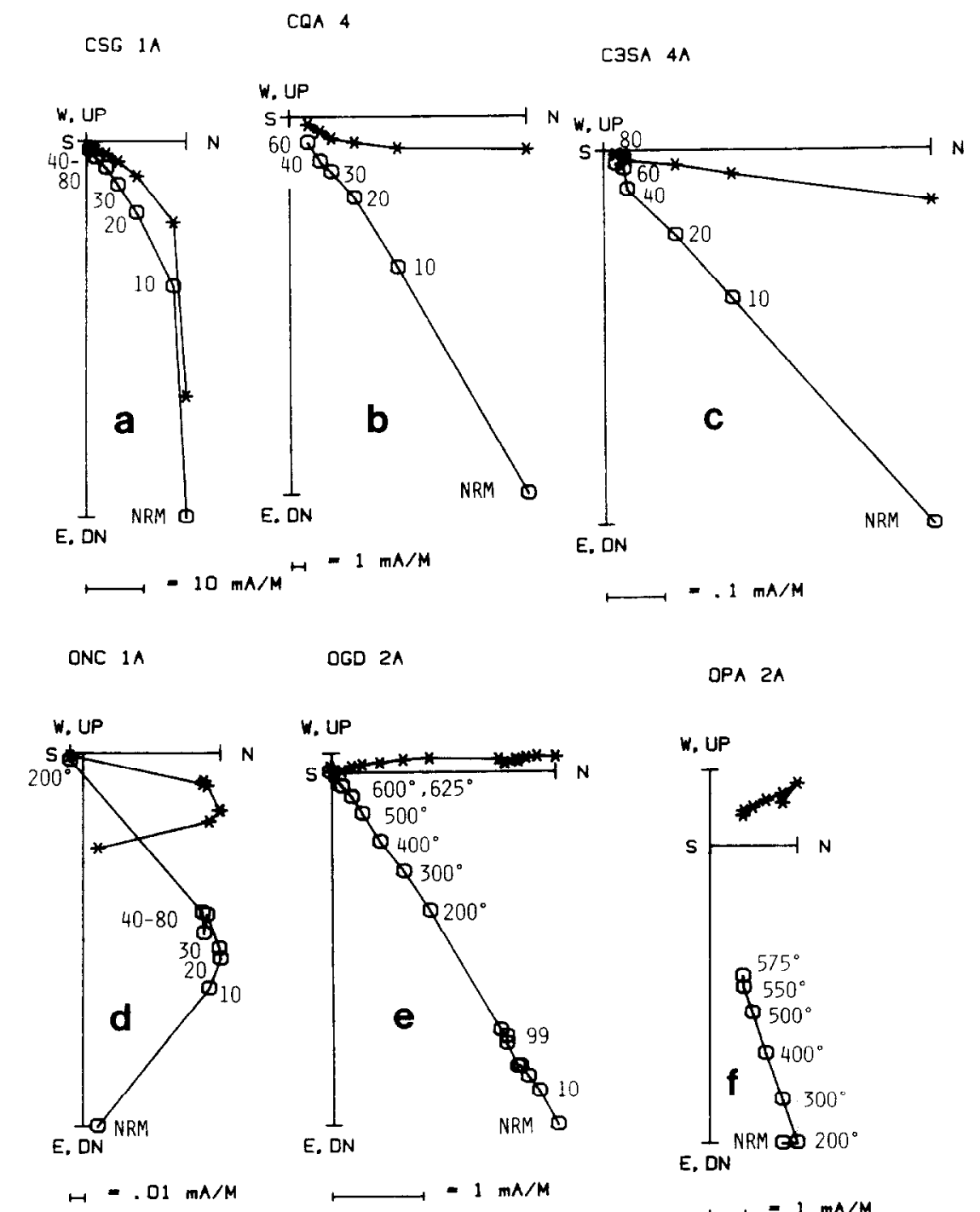

$\operatorname{OGD} 2 A$

DPA $2 A$
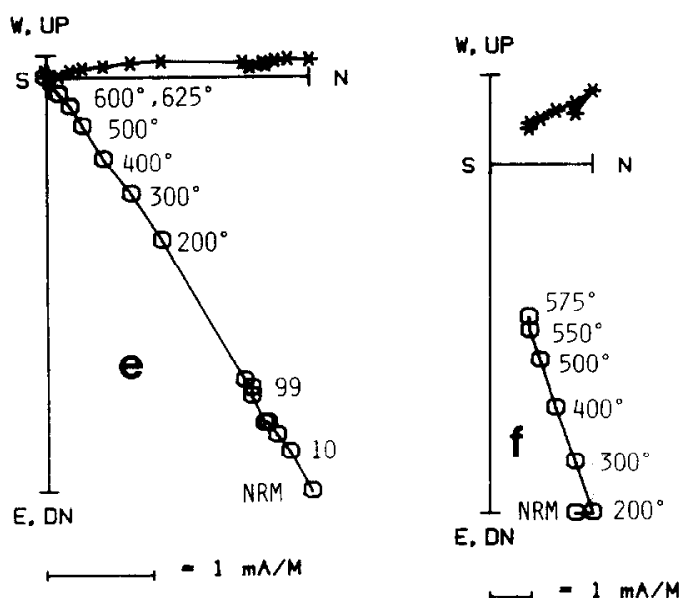

Fig. 2. Orthogonal plots of demagnetization data representative of formations $Y 1-Y 10(a-j)$ studied in the Yichang area. Open circles (stars) plotted on vertical (horizontal) axes in geographic coordinates. Numbers with degrees adjacent to data points are thermal demagnetization levels in Celcius; other treatment levels are AF demagnetization in millitesla. 


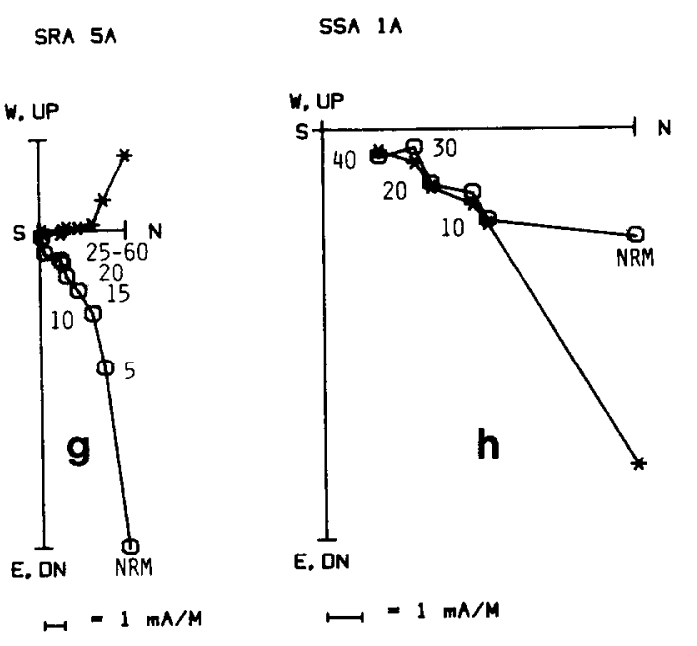

DHG 4 A

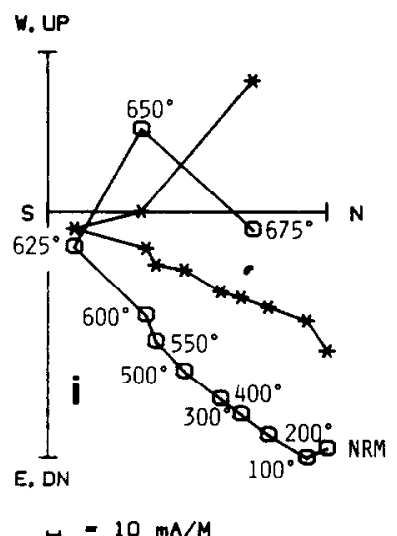

Fig. 2 (continued).

3a, b, h, k); stability of NRM to AF treatment is typically high (Fig. 3b, k) to very high (Fig. 3a). The demagnetization behavior of samples from N5 is unremarkable except that the single component magnetizations tend to be easterly and the NRM intensities are higher than in other limestone units (Fig. 3f, g). A more distinctive feature, the presence of dual polarity (northerly and down, normal, as well as southerly up, reverse), is however revealed in demagnetization of three of the units, the mauve-colored Silurian sandstone (N3), the red Devonian sandstone (N4) and the gray Permian limestone (N8). In N3 the two polarities are rarely seen in the same sample but can occur in different samples from the same site; the demagnetization behavior of samples with either normal or reverse polarity is nevertheless other- wise virtually identical, with unblocking temperatures distributed up to about $650^{\circ} \mathrm{C}$ (Fig. 3c, d). In units $\mathrm{N} 4$ and N7, however, both polarities can occur as separate components within an individual sample. In both these units, a high coercivity reverse component is revealed in some samples after the removal of a lower coercivity normal component; the reverse component has unblocking temperatures as high as $670^{\circ} \mathrm{C}$ (Fig. 3e, j). In other samples only the normal polarity component seems to be present, with unblocking temperatures that tend to be lower than for the reverse component but which can still be $600^{\circ} \mathrm{C}$ or more (Fig. 3i). Judging from the high unblocking temperatures of dual polarity units (N3, N4 and N7), hematite is likely to be an important contributor to remanence in these rocks despite the lack of obvious red coloration in two of them (N3 and N7).

\section{Analysis of results}

About $83 \%$ of the samples measured provided interpretable demagnetization trajectories. In the remaining samples, progressive demagnetization generally did not reveal any systematic behavior, usually because of instability of magnetization but frequently also because of weak NRM intensities. In the case of samples with dual polarity directions in units N4 and N7, only the final component was calculated for further statistical analysis.

In the Yichang area, bedding variation within any sampled formation is with one exception less that $7^{\circ}$ and the only opportunity to make a semblance of a fold test was for unit Y4. The bedding at three sites in $\mathrm{Y} 4$ dipped $10^{\circ}-15^{\circ} \mathrm{E}$ and at five sites dipped $10^{\circ}-24^{\circ} \mathrm{S}$. The precision parameter before tilt corrections are made is a factor of 3.1 larger than after tilt corrections for the cight sites. The fold test is therefore negative at the 95\% confidence level (McElhinny, 1964) and the magnetizations of this lower Ordovician limestone are clearly secondary and post-Jurassic in age.

In the Nanjing area, bedding variation within the sampled formations was generally greater than at Yichang but sufficient in only two units, N2 and $\mathrm{N} 7$, to provide a statistically decisive fold or 
tilt test. In these two cases, because of the relatively large number of sites (N2) or a relatively large tilt variation of about $60^{\circ}$ (N7), negative fold tests significant at $95 \%$ and $99 \%$ confidence levels, respectively, were obtained. Unit N7 (Fig. 4) is especially interesting because both polaritics occur; before tilt correction the averages of the normal and reverse sites are within $3^{\circ}$ of antiparallel but become more than $25^{\circ}$ from antiparallel after tilt correction. This supports the secondary nature of the magnetizations already inferred from the negative fold test, even though opposite polarities are sometimes taken as evidence for original or primary magnetizations. For the other six units from Nanjing, the precision parameters do not change significantly after tilt corrections.

\section{IRM experiments}

Isothcrmal remanent magnetization (IRM) acquisition and thermal demagnetization experiments on some representative samples of the limestones are shown in Fig. 5. The spectrum of IRM properties can be categorized into four types. A dominant, very high coercivity phase (saturation IRM clearly not reached by $0.8 \mathrm{~T}$ ) characterizes type I and II. For type I, there is a large reduction in IRM after demagnetization to only about

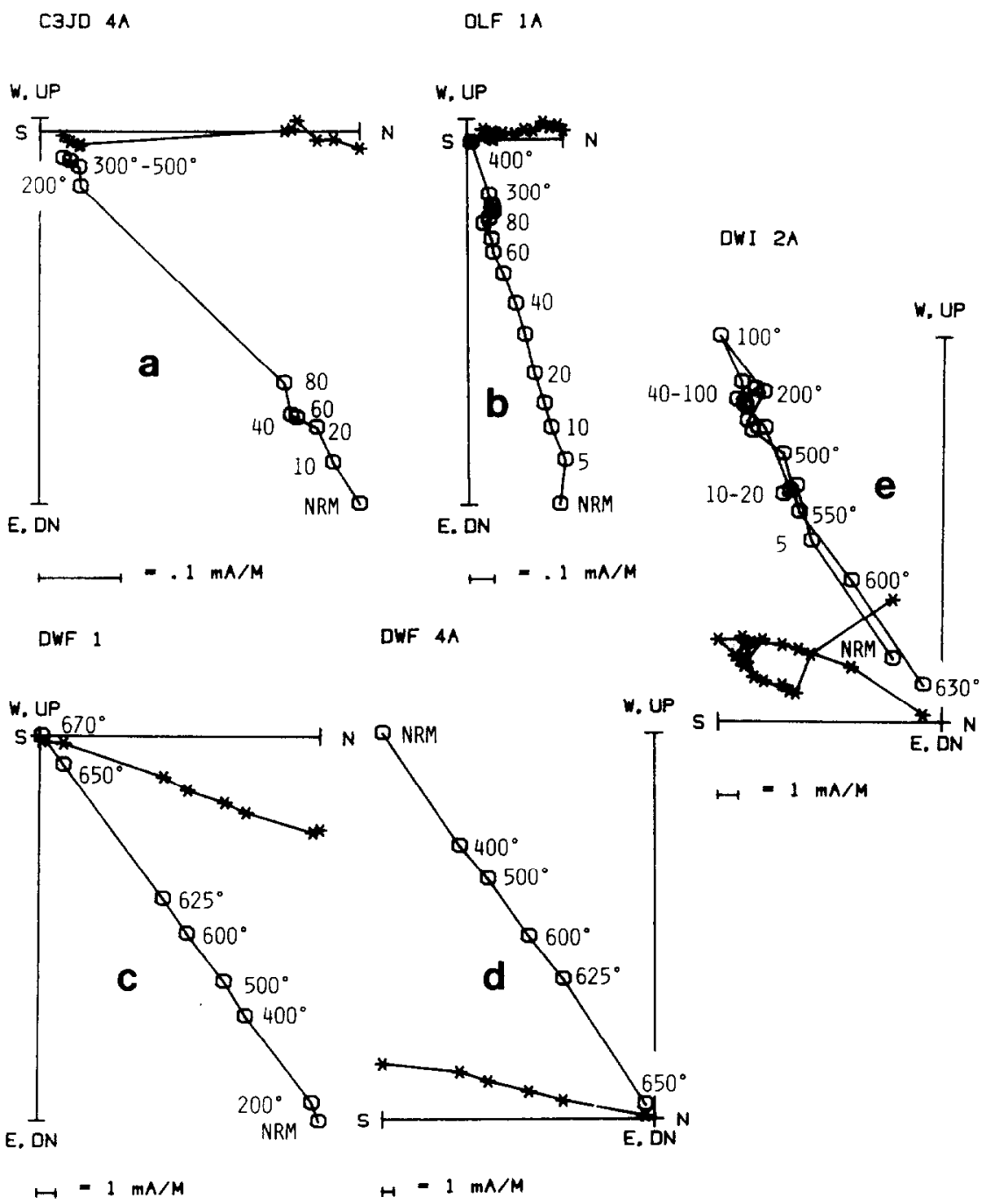

Fig. 3. Orthogonal plots of demagnetization data representative of formations N1 to N8 from the Nanjing area. (a) N1; (b) N2; (c, d) N3; (e) N4; (f, g) N5; (h) N6; (i, j) N7; (k) N8. Conventions as in Fig. 2. 
CLKC 1A

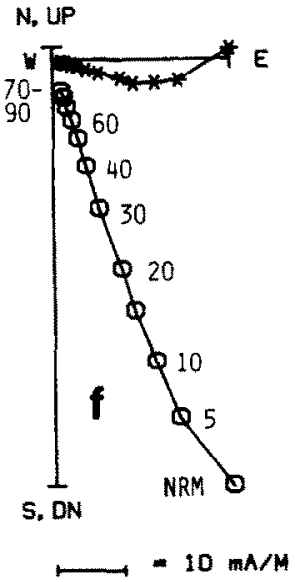

POK 5A

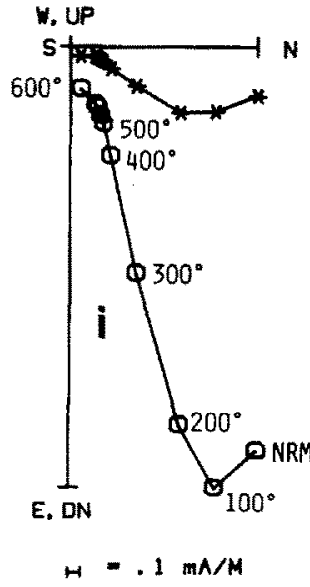

CLKD 2B

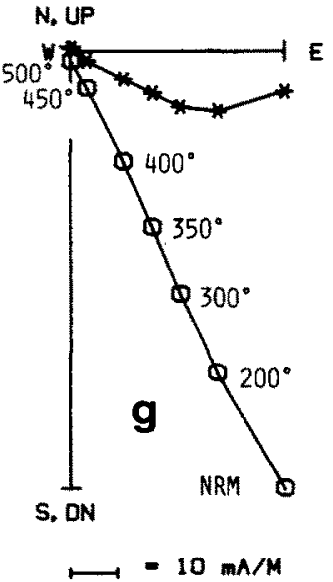

POL 2A

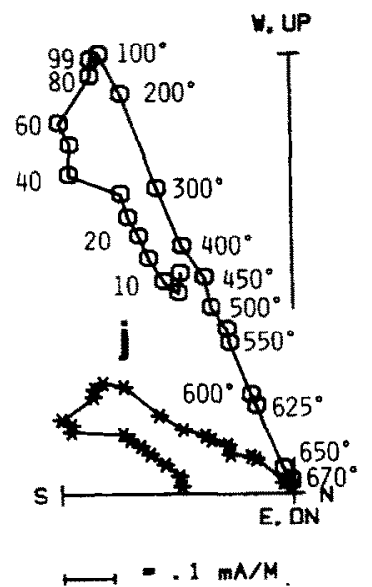

CUCA $2 A$

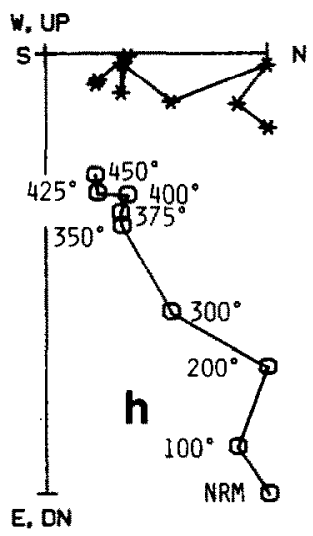

$H=.1 \mathrm{~mA} / \mathrm{M}$

TCA $5 \AA$

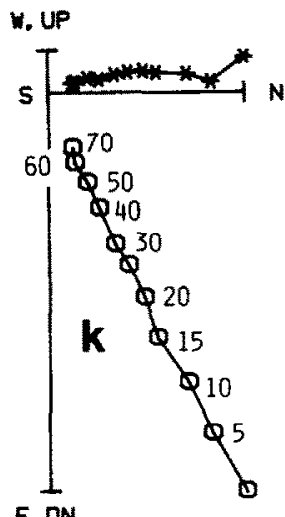

$E$, DN

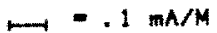

Fig. 3 (continued).

$100^{\circ} \mathrm{C}$ (Fig. 5, a) whereas demagnetization temperatures can extend to about $680^{\circ} \mathrm{C}$ for type II (Fig. 5, b). Type I behavior, observed most prominently in unit Y4 but also observed in some samples from N1, is consistent with a contribution from high coercivity, low blocking temperature geothite. Type II behavior, seen in the reddish-colored limestones of units Y5 and Y6 but also in the drab limestones of N6 and N7, is most probably due to the presence of high coercivity, high blocking temperature hematite. More commonly observed, however, is type III behavior, characterized by saturation IRM achieved by 0.1 to 0.2 $\mathrm{T}$ and maximum unblocking temperatures of around $400^{\circ} \mathrm{C}$ (Fig. 5, c). The identity of this low

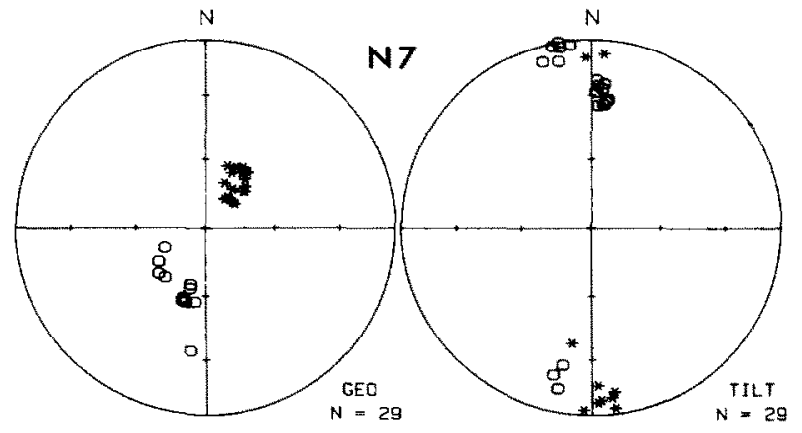

Fig. 4. Sample characteristic directions for Permian limestone N7 from Nanjing, plotted on equal-area projections before (left) and after (right) bedding tilt corrections, with open circles (stars) projected on upper (lower) hemispheres. Ratio of precision parameters before to after tilt corrections (and 95\% confidence test value) is 8.4 (2.97) for six sites converted to common polarity. 


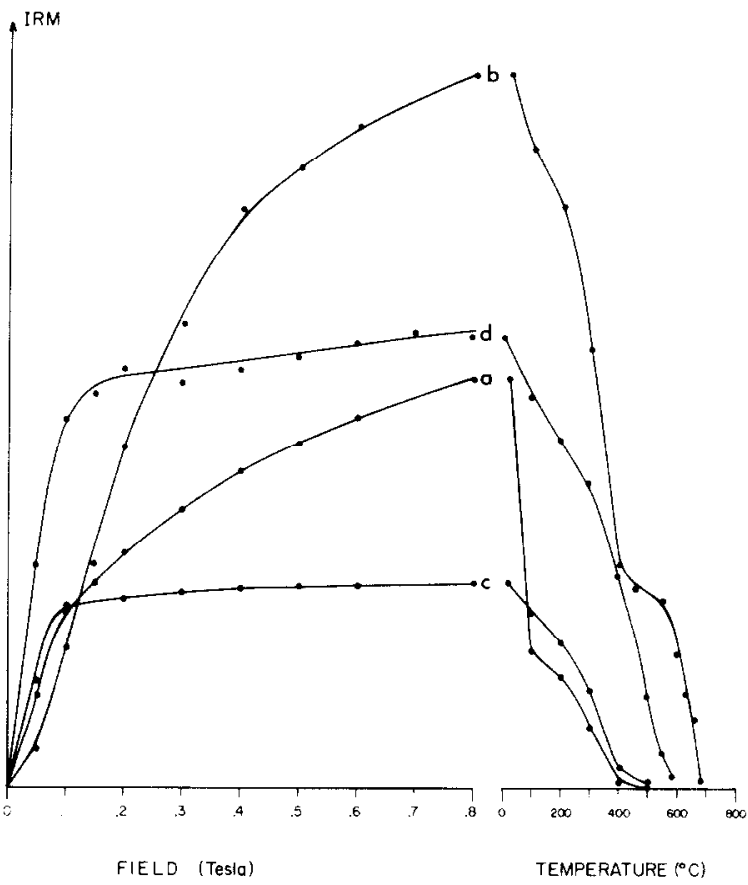

Fig. 5. Acquisition and thermal demagnetization of IRM (scaled in arbitrary units) in representative samples from Paleozoic limestone formations. $a$-sample OPD1 from Y6 (IRM $=1.2$ A $/ \mathrm{m}) ; b$-sample ONC2 from Y4 (IRM $=70 \mathrm{~mA} / \mathrm{m})$; $c$-sample OLD1 from N2 $($ IRM $=35 \mathrm{~mA} / \mathrm{m}) ; d$-sample CLKC1 from N5 $($ IRM $=0.26 \mathrm{~A} / \mathrm{m})$.

coercivity phase with moderate unblocking temperatures is uncertain; candidate minerals with requisite magnetic properties are maghemite, a titanium-bearing magnetite or even possibly pyrrhotite. In any case, this magnetic mineral phase appears to be present in many of the limestones studied, either essentially alone (Y1-Y3, Y7, Y10 and $\mathrm{N} 1$ ) or in conjunction with either goethite (Y4, N2; Fig. 5, $a$ ) or hematite (Y5, Y6, N7; Fig. $5, b)$. The only good evidence we have found for magnetite in the limestone units is expressed in the (type IV) IRM properties of N5 and N8, which are characterized by an approach to saturation IRM by about $0.2 \mathrm{~T}$ and maximum unblocking temperatures of $550^{\circ}-600^{\circ} \mathrm{C}$ (Fig. $5, d$ ).

\section{Paleopoles}

The site-mean directions were converted to virtual geomagnetic poles (VGPs) and these were averaged to obtain formation-mean paleopole positions and associated circles of confidence, both

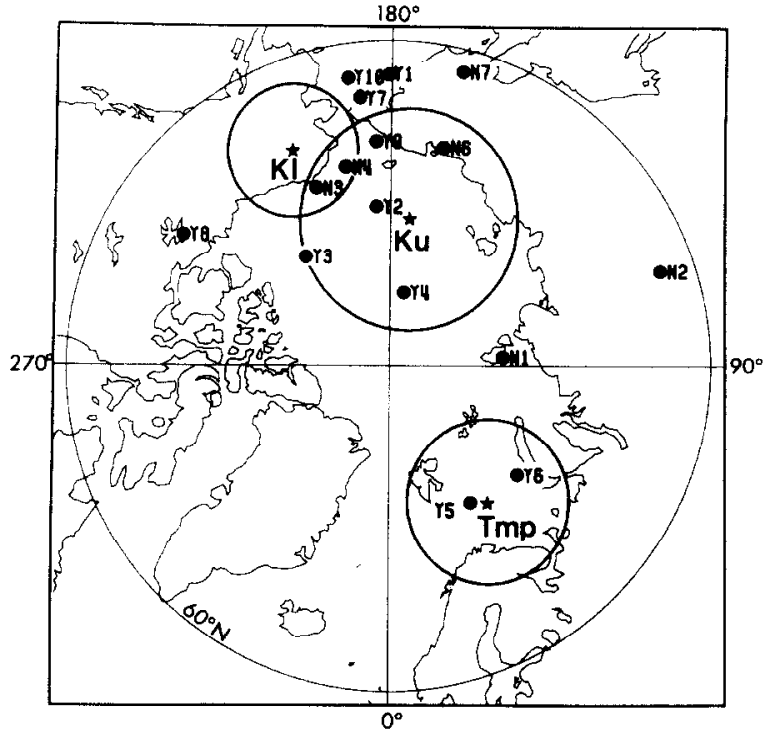

Fig. 6. Formation-mean paleopoles from Nanjing (N1-N4, N6, N7) and Yichang (Y1-Y10) (keyed to Table 1). These paleopoles are plotted without bedding tilt correction and are compared to an early Cretaceous pole (KJ; Lee et al., 1985), a late Cretaceous pole (Ku; Kent et al., 1986), and a middle to late Tertiary pole (Tmp; Lin et al., 1985) for South China.

in geographic and in bedding coordinates (Table 1).

Although the circles of confidence for all but two of the paleopoles (in geographic coordinates) do not include the present dipole field axis, twothirds of the formation paleopoles, however, group in the vicinity of late Mesozoic pole positions, in particular, those recently obtained from upper Cretaceous rocks from the Nanjing area (Kent et al., 1986) and from lower to middle Cretaceous sediments and volcanics from South Korea $\left(68^{\circ} \mathrm{N}\right.$, $205^{\circ} \mathrm{E}$; Lee et al., 1985), both with positive fold tests (Fig. 6). Considering the consistency and location of these paleopole positions, the wide age range of the formations and the convincing negative fold test on a member of this group (N7), it is plausible to draw the conclusion that these formations (Y1-Y4, Y7, Y9 Y10, N3, N4, N6, N7) were completely remagnetized in the late Mesozoic, most likely in the Cretaceous. Although normal polarity magnetizations are usually observed, the presence of reverse polarities in some of the units (N3, N4, N7) would suggest that some remagnetization also occurred prior to or after the Aptian to Santonian Cretaceous Long Normal Superchron 
(Lowrie and Alvarez, 1981; Kent and Gradstein, 1985).

Paleopoles for Y5, Y6, Y8, N1, N2 (Fig. 6) N5 and N8 (Fig. 7) nominally fall outside this apparent Cretaceous remagnetization direction. We do not attach much significance to pole Y8 (Silurian sandstones from Yichang) because it is based on only 10 samples from one site and may therefore be subject to very localized structural problems or remanence inhomogeneities that cannot be evaluated. Poles N1 and N2 are clearly remagnetized on the basis of negative fold tests whereas poles $\mathrm{Y} 5$ and $\mathrm{Y} 6$ fall near to a suggested middle to late Tertiary pole for South China $\left(74.2^{\circ} \mathrm{N}, 36.5^{\circ} \mathrm{E} A_{95}=7.6^{\circ}\right.$; Lin et al., 1985$)$. Thus these four poles (N1, N2, Y5, Y6) could conceivably record remagnetization along a Tertiary loop of apw for South China although it is not clear why only normal polarities should be preserved during the Tertiary period of frequent reversals.

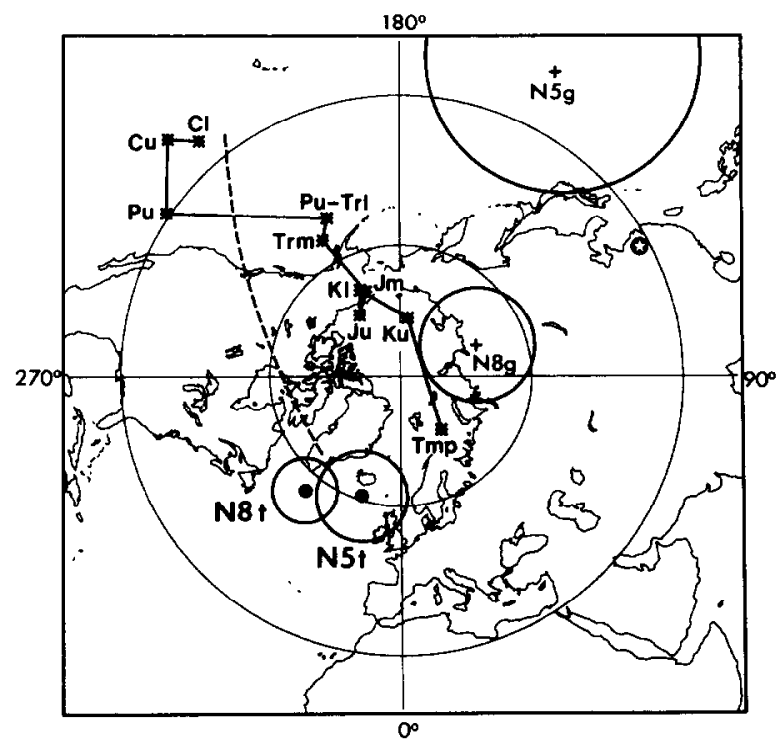

Fig. 7. Paleopoles N5 and N8, for lower Carboniferous and lower Triassic limestones from Nanjing, before (N5g, N8g) and after (N5t, N8t) bedding tilt corrections, compared to an apparent polar wander path seginent from lower Carboniferous (Cl) to middle to upper Tertiary (Tmp) for South China (after Lin et al., 1985, but using revised $\mathrm{KJ}$ and $\mathrm{Ku}$ poles discussed in text). Sampling location is shown by star. Dashed curve is small circle with respect to sampling location, i.e., the approximate trace of the N5t and N8T poles that would be expected for a rotation about a local vertical axis in the vicinity of Nanjing..
The results from two limestone formations from the Nanjing area, N5 (lower Carboniferous) and N8 (lower Triassic), may be exceptions to the general pattern of remagnetizations documented in the bulk of the units studied here. For N5, the easterly and down directions give a mean pole in geographic coordinates $\left(20^{\circ} \mathrm{N}, 153^{\circ} \mathrm{E}\right)$ that is far removed from documented late Mesozoic and younger paleopoles from South China (Fig. 7). Therefore the directions of $\mathrm{N} 5$ are not readily attributed to a post-folding remagnetization on this basis alone. For $\mathrm{N} 8$, the mean paleopole position in geographic coordinates is not incompatible with Tertiary remagnetization (Fig. 5). However, for both N5 and N8, it is interesting that the precision parameter increases significantly after tilt corrections, by a factor of 3.8 and 3.5 , respectively, when calculated according to sitemean VGPs even though there was no significant change in precision parameters when calculated for site-mean direction. We might therefore entertain the possibility that the magnetizations of N5 and N8 were acquired prior to folding.

\section{Discussion}

A principal if disappointing finding of this study is that most of the Paleozoic marine sedimentary units we sampled in the Nanjing and Yichang areas are demonstrated, or strongly suspected, to have suffered virtually complete remagnetization in late Mesozoic to Recent time. The main evidence for this is the grouping of most of these formation paleopoles in geographic coordinates near Cretaceous to Recent pole positions for South China, but it is not entirely circumstantial because statistically significant negative fold tests have been obtained on four of the units.

The remagnetization may be related to Yanshanian orogenic activity in the late Mesozoic in these areas of South China. Remagnetization events associated with orogenies elsewhere are now commonly documented, for example, during Jurassic to Paleocene Sevier/Laramide thrusting in the Rocky Mountains (Schwartz and Van der Voo, 1984), the Jurassic Nevadan orogeny in the Sierran foothills (Hannah and Verosub, 1980; Bogen et al., 1985) and the Permo-Carboniferous 
Alleghanian-Hercynian orogeny in the Appalachian-Caledonide belt on both sides of the Atlantic Ocean (Chamalaun and Creer, 1964; Creer, 1968; Roy and Morris, 1983).

The association of the secondary magnetizations with secondary magnetic minerals like geothite, hematite, and possibly maghemite in the limestones from South China suggests that the remagnetization was to large degree of chemical or diagenetic origin, such as has been proposed for remagnetized Jurassic limestones from the Jura Mountains of Switzerland and France (Johnson et al., 1984). The pervasive nature of the remagnetization in the two separate localities we studied in China moreover leads us to suspect that the remagnetization is not just of local significance. Indeed preliminary results of a paleomagnetic survey of Paleozoic rocks from Jiangsu, Zhejiang, Anhui and Hebei provinces of the South China block, and Shandong, Shanxi and Hebei provinces of the Sino-Korean (North China) block are reported to show a prevalence of negative fold tests and Mesozoic to Recent overprinting (Zhao and Coe, 1984). Nor were useful paleomagnetic data from Ordovician, Silurian or Devonian sites from South China obtained by Lin et al. (1985) because of cited remagnetization in Recent or Mesozoic directions. Unfortunately, Lin et al. (1985) report paleopole positions only in bedding coordinates so it is not possible to critically evaluate their entire paleomagnetic database for the North and South China blocks in light of the now strong evidence for remagnetizations.

In contrast, the magnetic properties of the lower Carboniferous (N5) and lower Triassic (N8) limestones from Nanjing indicate that the magnetic carrier in these two units is magnetite, which at least is not necessarily of secondary origin. Paleopole N5 in geographic coordinates does not correspond with expected remagnetized directions while there is a suggestion that the site-mean VGPs are better grouped after bedding tilt-corrections for both $\mathrm{N} 5$ and N8. On these admittedly tenuous bases, we explore the possibility that the stable magnetizations of $\mathrm{N} 5$, and less convincingly N8, pre-date late Mesozoic folding and may even represent original magnetizations.

The tilt-corrected paleopoles for $\mathrm{N} 5\left(61^{\circ} \mathrm{N}\right.$, $\left.342^{\circ} \mathrm{E}\right)$ and $\mathrm{N} 8\left(56^{\circ} \mathrm{N}, 320^{\circ} \mathrm{E}\right)$ plot in the North Atlantic region whereas virtually all Paleozoic and Mesozoic poles for South China summarized by Lin et al. (1985) fall in the Pacific Ocean hemisphere (Fig. 7). The sense of this disagreement is primarily in declination and would imply a counterclockwise rotation of $60^{\circ}$ or more of the Nanjing area relative to the stable part of South China.

Although this hypothesized rotation needs to be better substantiated by further paleomagnetic study, the proximity of the Nanjing area to the southern extension of the major NNE-trending Tancheng-Lujiang fault zone is noteworthy (Fig. 1). More than $2000 \mathrm{~km}$ long, this transcurrent fault zone is regarded as having had up to 1000 $\mathrm{km}$ of left-lateral displacement, mostly in the Indosinian to Yanshanian movements (late Triassic to lower Cretaceous) (Yao and Fang, 1981). It therefore does not seem unreasonable to suggest that the Nanjing area may have experienced large counterclockwise tectonic rotations in response to this major left-lateral shear. Major tectonic offset on this fault zone apparently ended by the early Cretaceous, which is consistent with the lack of evidence for systematic rotation in Cretaceous directions from the Nanjing area (Kent et al., 1986).

\section{Acknowledgements}

Laboratory work supported by NSF grants EAR80-25867 and EAR83-13478. LamontDoherty Geological Observatory contribution 4081.

\section{References}

Achache, J., Courtillot, V. and Zhou, Y.X., 1984. Paleogeographic and tectonic evolution of Southern Tibet since Middle Cretaceous time: new paleomagnetic data and synthesis. J. Geophys. Res., 89: 311-339.

Bogen, N.L., Kent, D.V. and Schweickert, R.A., 1985. Paleomagnetism of Jurassic rocks in the Western Sierra Nevada metamorphic belt and its bearing on the structural evolution of the Sierra Nevada Block. J. Geophys. Res., 90: 4627-4638.

Chamalaun, F.H. and Creer, K.M., 1964. Thermal demagnetization studies of the Old Red sandstone of the Anglo-Welch cuvette, J. Geophys. Res., 69: 1607-1616.

Creer, K.M., 1968. Paleozoic palaeomagnetism, Nature, 219: $246-250$. 
Hannah, J.L. and Verosub, K.L., 1980. Tectonic implications of remagnetized upper Paleozoic strata of the northern Sierra Nevada. Geology, 8: 520-524.

Johnson, R.J.E., Van der Voo, R. and Lowrie, W., 1984. Paleomagnetism and late diagenesis of Jurassic carbonates from the Jura Mountains, Switzerland and France. Geol. Soc. Am. Bull., 95: 478-488.

Kent, D.V. and Gradstein, F.M., 1985. A Cretaceous and Jurassic geochronology. Geol. Soc. Am. Bull., 96: 1419-1427.

Kent, D.V., Xu, G., Huang, K., Wen-You, Z. and Opdyke, N.D., 1986. Paleomagnetism of upper Cretaceous rocks from South China. Earth Planet. Sci. Lett., 79: 189-184.

Kirschvink, J.L., 1980. The least-squares line and plane and the analysis of palaeomagnetic data. Geophys. J.R. Astron. Soc., 62: 699-718.

Lee, G., Besse, J. and Montigny, R., 1985. Asia in the Cretaceous: new paleomagnetic data from South Korea and a new look at Chinese and Japanese data. Eos, Trans. Am. Geophys. Union, 12: 864.

Lin, J-L., Fuller, M. and Zhang, W-Y., 1985. Preliminary Phanerozoic polar wander paths for the North and South China blocks. Nature, 313: 444-449.

Lowrie, W. and Alvarez, W., 1981. One hundred million years of geomagnetic polarity history. Geology, 9: 392-397.

McElhinny, M.W., 1964. Statistical significance of the fold test in palaeomagnetism. Geophys. J. R. Astron. Soc., 8: $338-340$.

McElhinny, M.W., Embleton, B.J.J., Ma, X.H. and Zhang, X.K., 1981. Fragmentation of Asia in the Permian. Nature, 293: 312-216.

Roy, J.L. and Morris, W.A., 1983. A review of paleomagnetic results from the Carboniferous of North America; the concept of Carboniferous geomagnetic field horizon markers. Earth Planet. Sci. Lett., 65: 167-181.

Schwartz, S.Y. and Van der Voo, R., 1984. Paleomagnetic study of thrust sheet rotation during foreland impingement in the Wyoming-Idaho overthrust belt. J. Geophys. Res., 89: $10,077-10,086$.

Yao, Y. and Fang, Z., 1981. Brief report on the "Symposium on Tancheng-Lujiang Fault Zone". Seismol. Geol., 3 (2): 78-80 (with Engl. abstr.).

Zhang, Zh.M., Liou, J.G. and Coleman, R.G., 1984. An outline of the plate tectonics of China. Geol. Soc. Am. Bull, 95: 295-312.

Zhao, X. and Coe, R.S., 1984. Preliminary results of a paleomagnetic study of Paleozoic rock units from eastern China. Eos, Trans. Am. Geophys. Union, 65: 683 (abstr.).

Zijderveld, J.D.A., 1967. A.C. demagnetization of rocks: analysis of results. In: D.W. Collinson, K.M. Creer and S.K. Runcorn (Editors), Methods in Paleomagnetism. Elsevier, Amsterdam, pp. 254-286. 